\title{
DETERMINATION OF THE ENERGY PERFORMANCE OF A HELICOPTER IN A HOVER
}

\author{
T. Bulín*, D. Rozehnal ${ }^{* *}$
}

\begin{abstract}
This paper deals with the calculation and measurement of aerodynamic characteristics in the hover of a radio-controlled helicopter. After a brief introduction of the efficiency and adaptation conditions of the rotors, the article focuses on the determination of the power envelope and specific power of the helicopter propulsion unit. The main purpose is to familiarize the reader with the calculation of the energy intensity of the helicopter in the hover and its verification by laboratory measurement. The calculation is done by using the ideal propulsion theory and simplified blade element theory. The final discussion focuses on the determination of the energy performance of a helicopter in a hover.
\end{abstract}

Keywords: unmanned aerial vehicle, rotor, helicopter hover, aerodynamic characteristics, energy intensity

\section{Introduction}

Speaking of today's supply unmanned aerial vehicles (UAV) and their performance, the question of their economic operation has been largely addressed. The efficiency of their usage and economical savings is tested and examined in various meteorological conditions - as well as by large transport aircraft. Particularly for helicopters and multicopters, numerical applications are established to determine, for example, the necessary changes of size of main and tail rotor to achieve the required performance in transition to higher altitudes. However, by UAV electric power units, it is more common to change the rotor rotational speed instead of size transformation. It can be achieved by varying the input voltage (changing the number of battery cells) or changing the electric motor with different revolution per volt (Roubíček, 2004).

These changes are limited by the optimum operating mode of the power unit. Generally speaking, greater deviation from the optimum working point goes hand in hand with a greater energy loss. Moreover, this result, if we put it in a relation to the lower efficiency of the aircraft performance, causes the shorter duration of flight or hover of the helicopter (Petrásek, 2012). Based on this, during measurement of aerodynamic characteristics, we also have to specify power consumption of power unit and power envelope of the helicopter. By combustion engines, it also causes savings in fuel consumption and reduction of emissions. The aim of this paper will be to find the optimum working mode for the Mikado LOGO 600 3D acrobatic helicopter in hover by using two mathematical theories (ideal propulsion theory and simplified blade element theory) verified by laboratory measurement.

\section{Calculation of power consumption}

The ideal propulsion theory contains no data about the rotor construction, but provides a basic physical idea of its performance and efficiency, assuming that the propeller operates in the non-viscosity fluid and the speed of flow is accelerating equally across the whole rotor disc (Daněk, 2009). If the thrust which is

Ing. Tomáš Bulín.: Department of Air Force and Aircraft Technology, University of Defence; Kounicova 65; 662 10, Brno; CZ, tomas.bulin@unob.cz

** doc. Ing. Dalibor Rozehnal, Phd.: Department of Air Force and Aircraft Technology, University of Defence; Kounicova 65; 662 10, Brno; CZ, dalibor.rozehnal@unob.cz 
needed is a known variable (in hover the thrust is equal to gravity force of helicopter), it is possible to calculate its required power by using its characteristic speed. The rotation speed of the main rotor (MR) and the power which is required will help us to determine the rotor reaction moment. This moment can be eliminated by a side force which is produced by the tail rotor (TR) as a thrust to avoid rotation of the helicopter around the MR axis of rotation. Again, it calculates required power to TR by using its characteristics speed. By the sum of the MR and TR inputs, we obtain the necessary power that has to be transmitted from the accumulator through the transmission system, which has some inevitable losses (Leishman, 2006). According to these parameters, the necessary power input was calculated to $114.3 \mathrm{~W}$. In the case of an ideal $5 \mathrm{~s}$ battery pack with the output voltage of $20 \mathrm{~V}$ and the capacity of $4000 \mathrm{mAh}$, the flight time in hover is 42 minutes.

The results are overly overestimated, therefore the experimental aerodynamics uses a more accurate theory of blade element theory which determines the rotor aerodynamic factors. In this case, a simplified theory will be used to calculate the forces related to the referential control radius which is located at $70 \%$ of rotor length measured from the rotor head. This simplification can be done because of the symmetrical and non-twisted profile of blades with the same angle across the entire length. It is necessary to know the dimensionless coefficient of thrust, lift, edge losses and power to provide the total thrust and efficiency (Šveda, 1995). In our case, the helicopter power consumption was $175 \mathrm{~W}$. Application of the same battery mentioned before creates load equal to $8.8 \mathrm{~A}$. The duration of the flight in hover lasts

$$
t=\frac{C_{A K U}}{I}=\frac{4}{8,8}=0,45 \mathrm{hrs}=27 \mathrm{mins}
$$

If we compare both theories, we can observe that thanks to aerodynamic influence on the helicopter in hover the required power increases by $62 \%$ and the flight duration gets shorter from 44 minutes to 27 min. In the next chapter, the results will be tested experimentally.

\subsection{Experimental verification}

To determine the aerodynamic characteristics of the helicopter, it was necessary to measure the following values: MR thrust, TR thrust, MR rotational speed, input voltage and current to electronic speed control (ESC), ambient temperature and pressure, and angle of attack (AoA - the angle between chord line of an airfoil and the relative wind vector) through the position of control levers on the remote control. To measure the MR and TR thrust and torque, a multi-component aerodynamic strain gauge weight was selected (Hnidka et al.). The height of the MR above platform was only $630 \mathrm{~mm}$, which is almost the radius of MR. For this reason, the whole measurement is influenced by the ground effect. A power from battery pack was replaced by two DC voltage sources with maximum voltage $32 \mathrm{~V}$ and current $60 \mathrm{~A}$. Before ESC the voltage and current by multimeter and Hall probe were measured. This eliminated the power loss from sources to ESC. To catch the MR rotational speed a second Hall probe was installed over the main gear wheel, sensing the change in the magnet polarity of the two magnets.

Helicopter control unit did not allow direct reading of setting AoA, so the relative scales on the surrounding walls was measured using fixed laser pointers on MR and TR. The shortest distances from the walls were determined as a zero AoA. These angles were later recalculated which was based on test measurements of the MR and TR thrust.

It was not possible to switch off the automatic regulation TR AoA to keep the flight straight even after disconnecting the gyro sensor, so the servomotor was connected directly to the radio receiver. This was followed by the adjustment AoA to linear waveform with zero setting approximately in the first third of the control (Pelikán, 2015). Increasing the MR AoA, control unit automatically introduces the forward tilt for the forward flight. It should be compensated by cyclic steering control, but in this case the whole measurement process would become more complicated. Although the MR is controlled by three servomotors arranged to a circle of $120^{\circ}$, it was selected a basic mode as a one servomotors with centralized collective. Then the zero AoA of each blade was set by trim buttons to obtain final thrust in axis of MR rotation. Changes of MR AoA were almost constant, but not the same on TR. Nevertheless, during the test measurements, the linear course of the MR and TR was confirmed, eliminating the hysteresis caused by the inaccurate operation of the control buttons, clearance of servomotors, their suspension and sensitivity. 
The maximum change of MR AoA was $20^{\circ}$ with average AoA change $0.545^{\circ}$ (36 adjustable positions). TR adjustment mechanism allows maximum change AoA of $55^{\circ}$ with average change of $1.6^{\circ}$. The collection and data recording was send through the NI measuring cards connected in CompactDAQ to the created LabView user environment. The current positions of all control levers were manually entered. Four sequences (without MR and TR; only MR, only TR, full configuration) was measured for voltage $16 \mathrm{~V}, 20 \mathrm{~V}, 26 \mathrm{~V}, 32 \mathrm{~V}$.

\section{Measurement}

Several calibrations had to be performed before each beginning of the measurement. In the first sequence without MR and TR, the power unit was measured. Setting the pulse-width modulation (PWM) from zero to maximum and back, for voltage $20 \mathrm{~V}$ and $32 \mathrm{~V}$, the power characteristics or the motor with transmission system were measured. Subsequently, the maximum PWM was set and the input voltage was gradually changed from $13 \mathrm{~V}$ to $32 \mathrm{~V}$ and back to engine stop $(9 \mathrm{~V})$. This has resulted in the maximum performance characteristics of the engine with transmission.

Other measurement sequences were run only with maximum PWM. During second and third sequence measurements, the constant voltage to the EER was always set and the AoA was changed from zero to maximum and back. Measuring input power and rotational speed with increasing load caused by the rotor, the maximum thrust and power characteristics of MR and TR were measured.

During the fourth sequence (full configuration) there was always effort to set the correct TR AoA to compensate torque to simulate a helicopter in hover or in vertical flight without rotation. Due to exceeding maximum permitted engine speed (over 10,000 rpm) and fear related to overheating and mechanical damage, the last measurement (32 V) was omitted (Mikado, 2017). During $20 \mathrm{~V}$ measurements, the helicopter exhibited increased vibration apparently associated with the resonance and stiffness of its entire structure. It caused some hysteresis between ascending and descending curve of setting AoA.

\section{Processing of measured data}

The MR and TR thrust coefficients were given by second and third sequences. With this knowledge, it is easy to calculate the usable rotor thrust at a specific adjustment of the helicopter. The power envelope of the helicopter is determined by displaying the MR thrust in full configuration for individual voltages, which is shown in Fig. 1. The power envelope represents the ability of the helicopter to fly. Voltage $16 \mathrm{~V}$ is not sufficient enough for the basic forward flight or hover. This effect can occur for example in case of fully discharged battery pack. In contrast, at a voltage of $26 \mathrm{~V}$ the helicopter produces a thrust twice more. Another important factor in the design of the required helicopter configuration is the power output of the propulsion unit (PU).

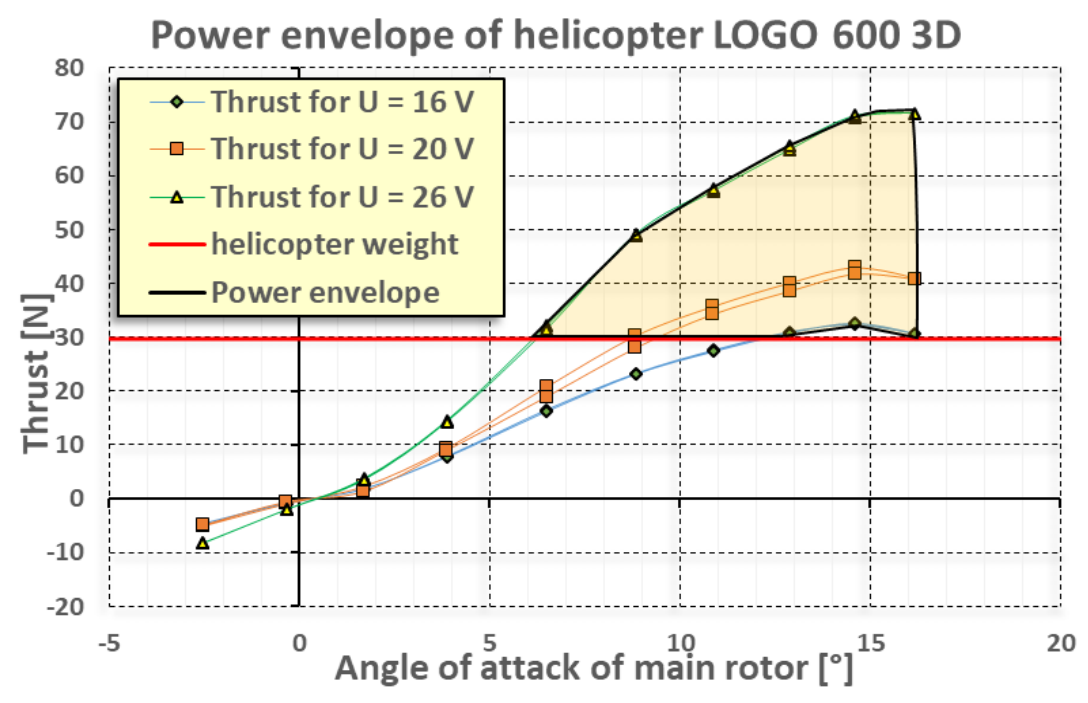

Fig. 1: Power envelope of helicopter

Although the thrust of rotors with more rotational speed is increasing, the PU is built only at certain operation regime. This is due to, for example, the increased blade drag by the second power with increase rotational speed. Therefore, the ratio of power per unit of thrust is used, which is shown in Fig. 2. The 
diagram allows to set the optimal supply voltage for given PU, but at the same time, the criterion was done so that the helicopter was able to fly.

The diagram shows that by $16 \mathrm{~V}$ at least the power per unit of thrust is consumed. It means that the PU works most economically (especially between AoA $8^{\circ}-12^{\circ}$ ). However, from the previous power envelope, the helicopter is already at the border that marks the ability of flight (AoA $\left.12^{\circ}\right)$. Therefore, for "normal flying" with sufficient thrust, the ideal voltage would be approximately 18-20 V. This voltage corresponds to the $5 \mathrm{~s}$ battery pack.

Specific power of helicopter power unit

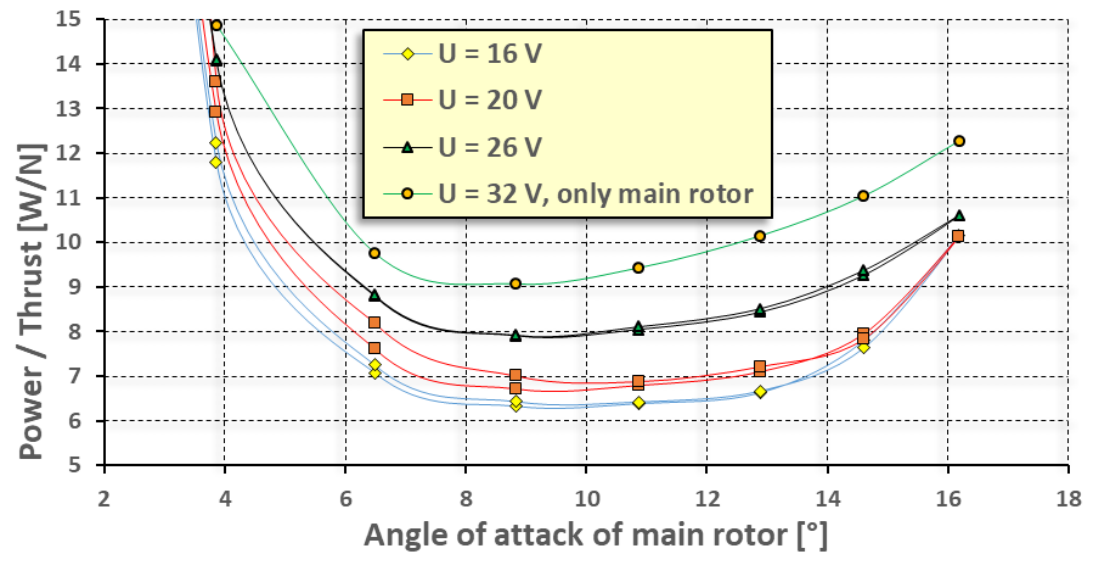

Fig. 2: Specific power of helicopter power unit

However, if a helicopter is meant to be used for aerobatic flying, a larger reserve of usable thrust is appreciated. It is therefore advisable to choose a higher supply voltage of $22 \mathrm{~V}$ and more. The optimal solution would be around $25 \mathrm{~V}$. The helicopter is able to produce a thrust two times more than its weight. By comparing the power output for $20 \mathrm{~V}$ and $26 \mathrm{~V}$, it can be deduced that at higher operation voltages the energy demand of PU in its optimal mode increases by $10-15 \%$ of the power consumed.

\section{Conclusions}

The record shows that the helicopter in hover with AoA 8,5 and MR rotational speed $845 \mathrm{rpm}$ has total input power $200 \mathrm{~W}$. On a drop voltage at $19,6 \mathrm{~V}$ the current consumption was $10,3 \mathrm{~A}$. In this case, the flight time of the helicopter in hover was shortened

$$
t=\frac{C_{A K U}}{I}=\frac{4}{10,3}=0,39 \mathrm{hrs}=23 \mathrm{~min}
$$

Thus the hovering time has been reduced almost twice compared to prediction related to the ideal propulsion theory. This difference in results, however, is correct because the ideal propulsion theory does not include the effect of aerodynamic forces. The difference of $25 \mathrm{~W}$ compared with simplified blade element theory is also affected by the ground effect, which contributes positively to the total thrust of MR. In real conditions without the ground effect, the helicopter's energy demand is even higher.

\section{References}

Daněk, V. (2009). Mechanika letu. CERM, Brno (in Czech)

Hnidka, J. and Rozehnal, D. (2016). Design and Construction of Weight Measuring Balance Plate. In: Transfer 2016, Trenčianska univerzita Alexandra Dubčeka v Trenčíně, Fakulta špeciálnej techniky, Trenčín.

Leishman, J. G. (2006) Principles of Helicopter Aerodynamics. $2^{\text {nd }}$ ed. Cambridge University Press, New York.

Mikado. (2014). Bauanleitung LOGO 600. [cit. 2017-06-04, from: http://shop.mikado-heli.de/LOGO-

Helicopters/LOGO-600-SX/LOGO-600SX.htm?shop=k_mikado_e\&SessionId $=\& a=$ article $\&$ ProdNr=02120\&t= $7567 \& \mathrm{c}=6442 \& \mathrm{p}=6442]$.

Pelikán, D. (2015) Aurora 9. [cit. 2017-06-03, from: http://www.pelikandaniel.com/?sec=product\&id=38080].

Petrásek, M. (2012) Konstrukce vrtulníku. Univesity of Defence, Brno (in Czech)

Roubíček, O. (2004) Elektrické motory a pohony: příručka techniky, volby a užití vybraných druhů. $1^{\text {st }}$ ed. BEN, Praha

Šveda, J. (1995) Practical helicopter aerodynamics. Military academy, Brno (in Czech) 